\title{
Pharmacological Modification of Bradykinin Induced Breakdown of the Blood-brain Barrier
}

\author{
Jennifer J. Raymond, David M. Robertson and Henry B. Dinsdale
}

\begin{abstract}
Internal carotid artery infusion of bradykinin caused extensive breakdown of the blood-brain barrier to protein as demonstrated by the extravasation of the marker, horseradish peroxidase, into vessel walls and the adjacent parenchyma. Pretreatment of the animals with indomethacin, trifluoperazine, or imidazole significantly reduced the quantity of abnormally permeable vessels as determined by light microscopy. By electron microscopy, it was determined that bradykinin caused an intense increase in the number of pinocytotic vesicles in the permeable segments, but no change in the interendothelial junctions. After imidazole pretreatment, although the extent of the permeability change was markedly reduced, the intensity of pinocytotic activity in the involved areas was not altered.
\end{abstract}

RÉSUMÉ: Modifications pharmacologiques de la barrière hémoencéphalique induites par la bradikinine. L'infusion de bradykinine dans la carotide interne cause des perturbations étendues au niveau de la barrière hémoencéphalique pour les protéines, comme en témoigne l'extravasation du marqueur, la peroxidase du raifort, dans les parois vasculaires et le parenchyme adjacent. Le traitement préalable des animaux à l'indométhacine, au trifluoperazine, ou à l'imidazole diminue de façon significative le nombre des vaisseaux sainguins dont la perméabilitié est altérée comme en témoigne la microscopie optique. A la microscopie électronique, nous constatons que la bradykinine cause une augmentation importante du nombre des vésicules pinocytotiques dans les segments perméables, sans provoquer de changement au niveau des jonctions interendothéliales. Même si l'ampleur des changements de perméabilité des vaisseaux est diminuée de façon importante par le prétraitement à l'imidazole, l'intensité de l'activité pinocytotique dans les régions touchées n'est pas modifiée.

Can. J. Neurol. Sci. 1986; 13:214-220

Increased permeability of the blood-brain barrier (BBB) is observed following various insults to the brain including acute hypertension, ${ }^{1,2}$ infusion of hyperosmolar solution $s^{3}$ and cryogenic lesions. ${ }^{4.5}$ Increased pinocytosis in endothelium of cerebral vessels and vasogenic brain edema is associated with all these animal models. Johansson ${ }^{6}$ found that pretreatment with thioridazine, trifluoperazine (TFP), desipramine or imidazole reduced albumin extravasation into the neuropil following an acute hypertensive insult. Treatment with these drugs also reduced horseradish peroxidase (HRP) extravasation 24 hours after a cold lesion. ${ }^{7}$

Bradykinin, a well-known peripheral vasodilator, ${ }^{8}$ has been localised within the mammalian brain ${ }^{9}$ and its action on vascular permeability has been implicated in the development of edema following brain injury. ${ }^{10}$ To date, studies on the action of bradykinin on mammalian brain have utilized intraventricular injections, ${ }^{11.12 .13}$ cranial window topical application, ${ }^{14.15 .16}$ or isolated cerebral vessels. ${ }^{17,18}$

In the present paper we tested the hypothesis that bradykinininduced BBB breakdown can be prevented or reduced by pre- treatment with imidazole, TFP or indomethacin. Under normal conditions, there is only a slight transfer of HRP and other proteins across the endothelium of cerebral vessels. When the vessels become "permeable" this rate is increased markedly, and the HRP reaction product allows the abnormal vessels to be located with ease at the LM and EM level.

\section{Methods}

Experiments were performed on 33 female Wistar rats weighing $180-200 \mathrm{~g}$.

\section{Drug Pretreatment}

Animals were divided into five groups. All groups received 3 pretreatment injections $(0.2 \mathrm{ml} / 100 \mathrm{~g}$ i.p. $)$. These were given intraperitoneally at 24 hours, 16 hours, and 1 hour before internal carotid infusion. The number of animals in each group is given in brackets.

Group 1: (6) $0.9 \% \mathrm{NaCl}$

Group 2: (9) $0.9 \% \mathrm{NaCl}$ 
Group 3: (6) Imidazole in $0.9 \% \mathrm{NaCl}(150 \mathrm{mg} / \mathrm{kg}$ in Ist and 3rd and $100 \mathrm{mg} / \mathrm{kg}$ in $2 \mathrm{nd}$ injection)

Group 4: (6) $1 \mathrm{mg} / \mathrm{kg}$ trifluoperazine (TFP) in $0.9 \% \mathrm{NaCl}$

Group 5: (6) $2.5 \mathrm{mg} / \mathrm{kg}$ indomethacin (Sigma) in $0.83 \mathrm{M} \mathrm{Na}_{2} \mathrm{CO}_{3}$ buffered to $\mathrm{pH}$ 7.6. Additional control animals were tested with $0.83 \mathrm{M} \mathrm{Na}_{2} \mathrm{CO}_{3}$ alone and were found to be the same as Group $\mathrm{I}$.

\section{Carotid Infusion}

Anaesthesia was induced by an intraperitoneal injection of sodium amytal $(10 \mathrm{mg} / 100 \mathrm{~g})$ approximately 15 minutes before the operation. Body temperature was maintained at $37^{\circ} \mathrm{C}$ using a heating pad. Blood pressure was monitored by placing a polyethylene catheter (PE90) attached to a Grass polygraph into the abdominal aorta. The left internal carotid artery was infused by retrograde insertion of a PE 10 catheter into the external carotid artery and advancing it to the origin of the internal carotid artery. Other arterial branches including the pterygopalatine, ascending pharyngeal and superior thyroid were litigated to ensure the infusate reached the left hemisphere of the brain. In initial experiments, trypan blue was infused into the internal carotid artery and its distribution throughout the left hemisphere was observed two minutes later.

All animals were infused at the rate of $0.39 \mathrm{ml} \mathrm{min}^{-1}$ for 3 minutes. Control animals (Group 1) were infused with $0.9 \%$ $\mathrm{NaCl}$ containing $12.5 \mathrm{mg} \mathrm{HRP}$ (horseradish peroxidase type II, Sigma) per ml. Animals in Groups $2-5$ received $0.9 \% \mathrm{NaCl}$, $1 \times 10^{-5} \mathrm{M}$ bradykinin, and $12.5 \mathrm{mg}$ HRP per ml. Thirty seconds later blood gases were measured and the rats perfused via the ascending aorta with $50 \mathrm{ml} 0.9 \% \mathrm{NaCl}$ followed by Karnovsky's fixative.

\section{Tissue Processing}

The cortex from left and right hemispheres was embedded in $6 \%$ agar and approximately fifty $50 \mu \mathrm{m}$ sections were cut using a Sorval TC-2 tissue sectioner. The sections were washed in $0.05 \mathrm{M}$ Tris $\mathrm{HCl}(\mathrm{pH} \mathrm{7.6)}$ and incubated for 20 minutes in 20 $\mathrm{ml}$ buffer containing $20 \mathrm{mg}$ 3,3-diaminobenzidine tetrahydrochloride (Sigma) and $0.2 \mathrm{ml} 1 \% \mathrm{H}_{2} \mathrm{O}_{2}{ }^{19}{ }^{19}$ Twelve sections were chosen randomly from the left cortex and mounted in aquamount (G.U.M.) for light microscopic morphometry. Appropriate areas of the remaining sections were processed for electron microscopy. Tissues were post fixed for 90 minutes in $1 \%$ osmium tetroxide, dehydrated through graded alcohols, infiltrated with propylene oxide and embedded in Epon 812. The tissues were flat embedded, enabling the vessels to be cut transversely. Ultrathin sections were examined unstained or stained with $7 \%$ uranyl acetate in methanol followed by lead citrate. ${ }^{20}$ An Hitachi H500 electron microscope was used at $75 \mathrm{KV}$.

\section{Quantitative morphometry}

i) Light microscopy: Ten cortical sections from each animal were photographed using a Zeiss photomicroscope and $\times 2.5$ objective. $5 \times 7$ inch prints were made giving a final magnification of $51.8 \times$. The area of cortex on each print was measured using a Zeiss MOP. Quantitative analysis of the vessel walls containing HRP were made by: a) measuring the length of the vessel and its branches using the MOP and b) placing a grid containing $0.25 \mathrm{~cm}$ squares over the print and counting the number of grid bars crossed by vessels containing HRP in their walls. Measurements were made by two independent observers who did not know the identity of the photomicrographs. ii) Electron microscopy: The number of pinocytotic vessels per $\mu \mathrm{m}^{2}$ of arteriolar endothelial cytoplasm was determined in permeable cortical vessels of five animals infused with bradykinin (Group 2) and non-permeable vessels from the corresponding vascular segments of four control animals (Group 2). Permeable vessels from four animals pretreated with imidazole prior to bradykinin infusion (Group 3) were also examined. A low power electron micrograph was taken of each vessel examined to determine vessel diameter. A series of overlapping electron micrographs were taken around the circumference of the arterioles at $26,000 \times$ magnification. The area of the endothelium was determined using a Zeiss MOP. Vesicles containing a definite unit membrane were counted within the endothelial cytoplasm. Vesicles at the luminal surface were counted only if they had a narrow neck and appeared to be pinching off from the surface.

\section{Results}

Infusion of $0.9 \% \mathrm{NaCl}$ containing $\mathrm{HRP}$ at a rate of $0.39 \mathrm{ml}$ $\min ^{-1}$ (Group 1) did not alter the mean arterial pressure (MAP) significantly (Figure 1). In animals receiving both HRP and bradykinin (Group 2) there was an immediate, transient blood pressure drop of approximately $25 \mathrm{~mm} \mathrm{Hg}$ which lasted for about 30 seconds. This was followed by a gradual increase to near control levels by the end of the 3 minute infusion (see Figure (A). The lowest MAP recorded for each animal did not fall below $80 \mathrm{~mm} \mathrm{Hg}$. Pretreatment with imidazole (Group 3). TFP (Group 4) or indomethacin (Group 5) did not significantly alter BP response to bradykinin and HRP infusion (Figure I B, $\mathrm{C}$, and $\mathrm{D})$. Blood gases were taken at the end of the infusions and animals with a $\mathrm{pO}_{2}$ less than $80 \mathrm{~mm} \mathrm{Hg}$ or a $\mathrm{pCO}_{2}$ greater than $50 \mathrm{~mm} \mathrm{Hg}$ were eliminated from the study. $\mathrm{PH}, \mathrm{pO}_{2}$ and $\mathrm{pCO}_{2}$ did not differ among the groups.

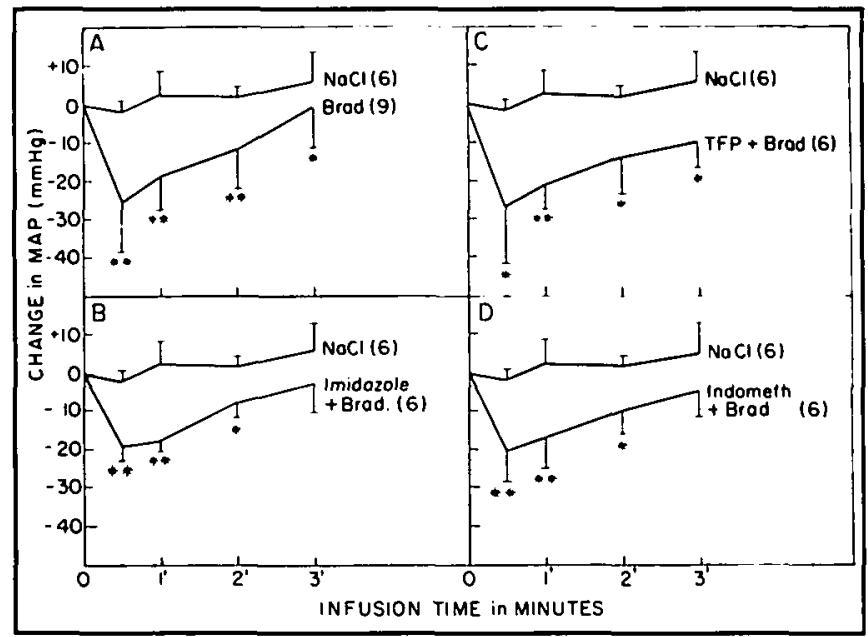

Figure I - Change in mean arterial pressure during internal carotid artery infusion of bradykinin. Resting MAP of A. Group l $(\mathrm{NaCl})=115 \pm$ $15 \mathrm{~mm} \mathrm{Hg}$ : Group 2 (bradykinin) $=114 \pm 7 \mathrm{~mm} \mathrm{Hg:B}$. Group 3 (Imidazole pretreatment. bradskinin) $=108 \pm 14 \mathrm{~mm} \mathrm{Hg}$. C. Group 4 (TFP pretreatment, bradykinin) $119 \pm 6 \mathrm{~mm} \mathrm{Hg}: D$, Group 5 (Indomethacin, bradykinin) $=107 \pm 9 \mathrm{~mm} \mathrm{Hg}$.

* significantly different from Group $1 p<0.01$

** significantly different from Group I $p<0.001$ 


\section{L.M. Study}

A representative slice from the left cortex of a rat in Group 1 receiving a $\mathrm{NaCl}$ infusion (Figure 2) shows no $\mathrm{BBB}$ disruption, whereas a rat in Group 2 (Figure 3) infused with bradykinin, displays extensive uptake of HRP into vessel walls. Sections from the right cerebral hemisphere rarely demonstrated the presence of HRP. There is a large involvement of very small arterioles in this model of BBB breakdown. This feature is seen more clearly in Figure 4 in which small arterioles have a high concentration of HRP. Infusion of bradykinin therefore produces significant BBB breakdown. The extent of this BBB breakdown is seen in Figure 5. A highly significant increase in the number of vessels containing HRP is found in animals infused with bradykinin $(p<0.001$ measuring length of positive vessels and $p<0.0001$ when the number of grid bars crossed by positive vessels are quantitated).

Pretreatment with imidazole, TFP or indomethacin significantly reduced the number of leaking vessels $(p<0.05$ for all groups), however it did not reduce the number to control levels. Groups 3, 4 and 5 all had significantly more vessels containing HRP than animals in Group $1(p<0.05$ by both methods). The extensive BBB breakdown produced by brady-

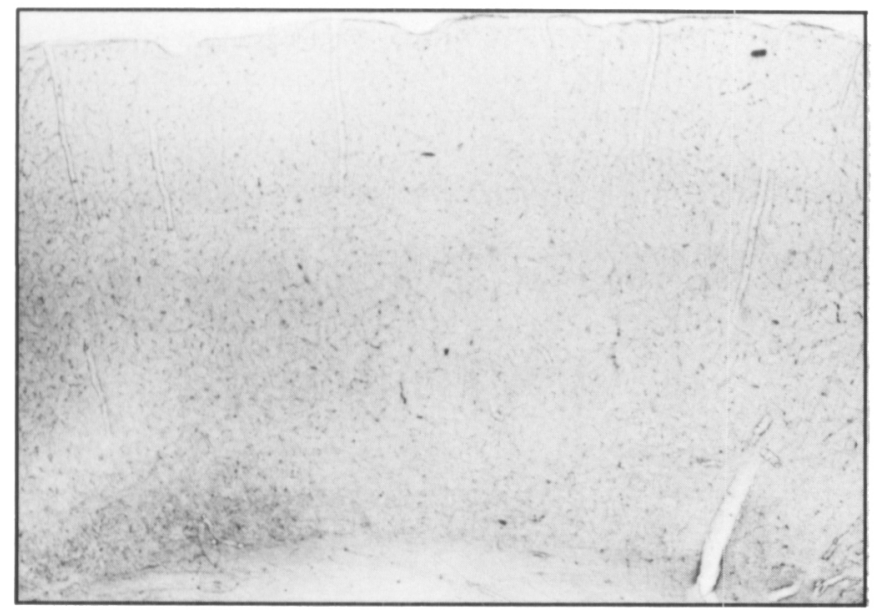

Figure 2-Mag. x 28.8. Group I (NaClinfusion). Note the absence of HRP from the cortex.

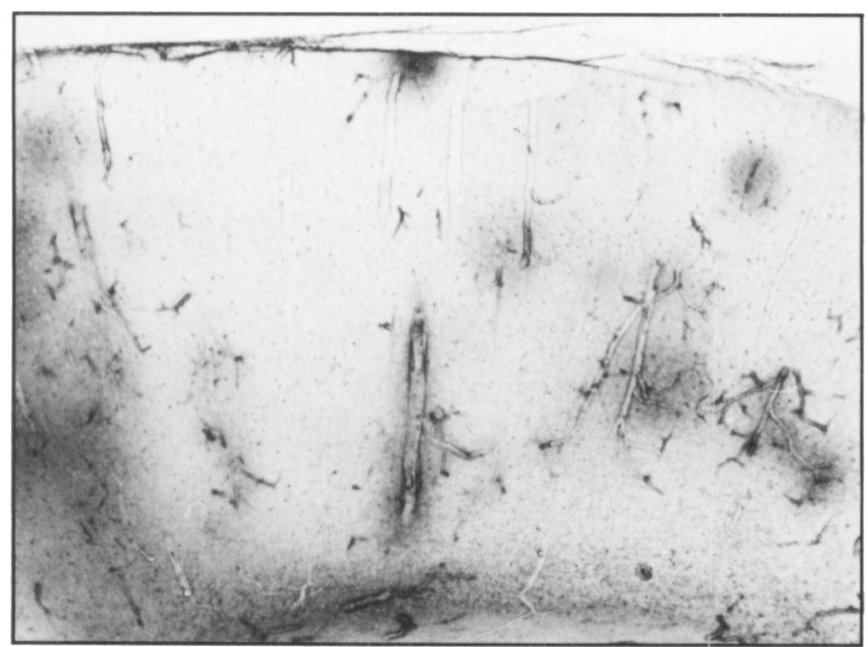

Figure 3-Mag. $x$ 28.8. Group 2. (Bradykinin infusion) Numerous vessels contain and are surrounded by extravassated HRP kinin infusion can be reduced by the pharmacological action of imidazole, TFP or indomethacin.

\section{E.M. Study}

Four control animals infused with $\mathrm{NaCl}$ (Group 1), five animals infused with bradykinin (Group 2) and four animals infused with bradykinin following imidazole pretreatment (Group 3) were studied by EM. Arterioles were defined as vessels possessing smooth muscle cells in their walls.

The 27 arterioles from Group 1 rarely contained HRP, and only an occasional vesicle containing HRP was observed. There was no apparent morphological difference between the 33 permeable vessels from animals in Group 2 and the 22 studied in Group 3. HRP was present in the majority of pinocytotic vesicles and in the basement membrane, smooth muscle and adventitial cells surrounding the endothelium (Figure 6). Vesicles containing HRP were occasionally seen at the basement mem-

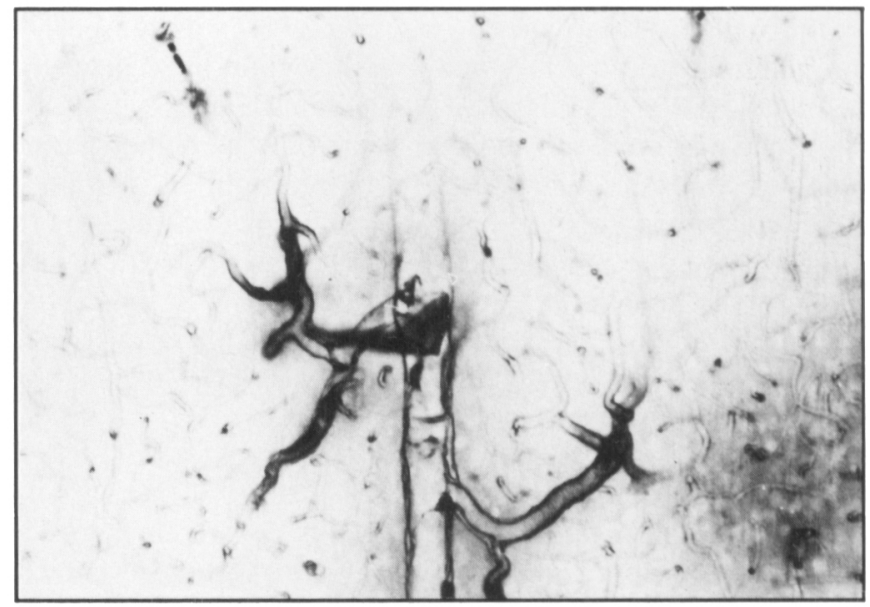

Figure 4-Mag. $\times$ 140. Group 2. (Bradykinin infusion) The arteriole in centre field displays a typical distribution of $H R P$ reaction product.

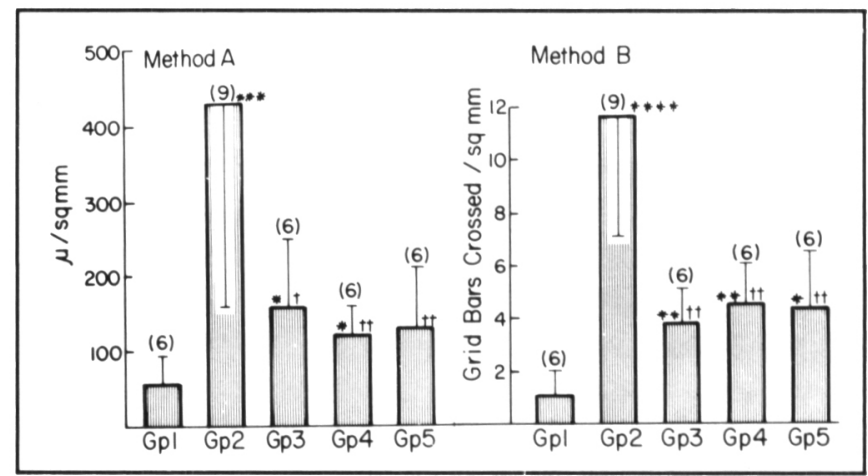

Figure 5-Quantitation of permeable vessels following bradykinin infusion Method A. Measurement of the length of HRP positive vessels in microns per sq $\mathrm{cm}$ cortex using a Zeiss MOP.

Method B. The number of grid bars crossed by HRP positive vessels. (For details, see methods).

**** significantly different from Group I $p<0.001$

*** significantly different from Group $I p<0.005$

** significantly differem from Group I $p<0.01$

* significantly different from Group $I p<0.05$

++ significantly different from Group $2 p<0.01$

+ significantly different from Group $2 p<0.05$

Pretreated Groups 3, 4, 5 were not significamly different from each other. Error bars denote S.D. number of animals is given in brackets. 
brane depositing their contents into the subendothelial space (Figure 7). A similar observation was made by $\mathrm{Nag}$ et al in the acute hypertension model. ${ }^{2}$ Junctions between endothelial cells appeared intact in both Groups 2 and 3 (Figures 7, 8). Cerebral edema was present in rats infused with bradykinin, particularly surrounding the small arterioles (Figure 6) where astrocytic foot processes were frequently swollen.

The pinocytotic vesicles were counted in a large number of vessels in each group. Vessels were divided into groups according to their diameter; small (less than $10 \mu \mathrm{m}$ ); medium $(10-18 \mu \mathrm{m})$; large (over $18 \mu \mathrm{m})$. The results are given in Table 1. The vessels examined in Group 1 contained very little HRP and only an occasional pinocytotic vesicle contained reaction product. The density of pinocytotic vesicles remained relatively constant, regardless of diameter, ranging from 4.5 to 7.3 vesicles per $\mu \mathrm{m}^{2}$. Permeable vessels in Group 2 contained significantly more pinocytotic vesicles than Group 1. Small and medium vessels contained more pinocytotic vesicles per $\mu \mathrm{m}^{2}(14.9 \pm 5.0$ and $15.0 \pm 4.9)$ than vessels over $18 \mu \mathrm{m}$ in diameter $(9.2 \pm 2.6)$. This represents a 3.3 fold increase $(p<0.001)$ in small arterioles, 2.1 fold $(p<0.002)$

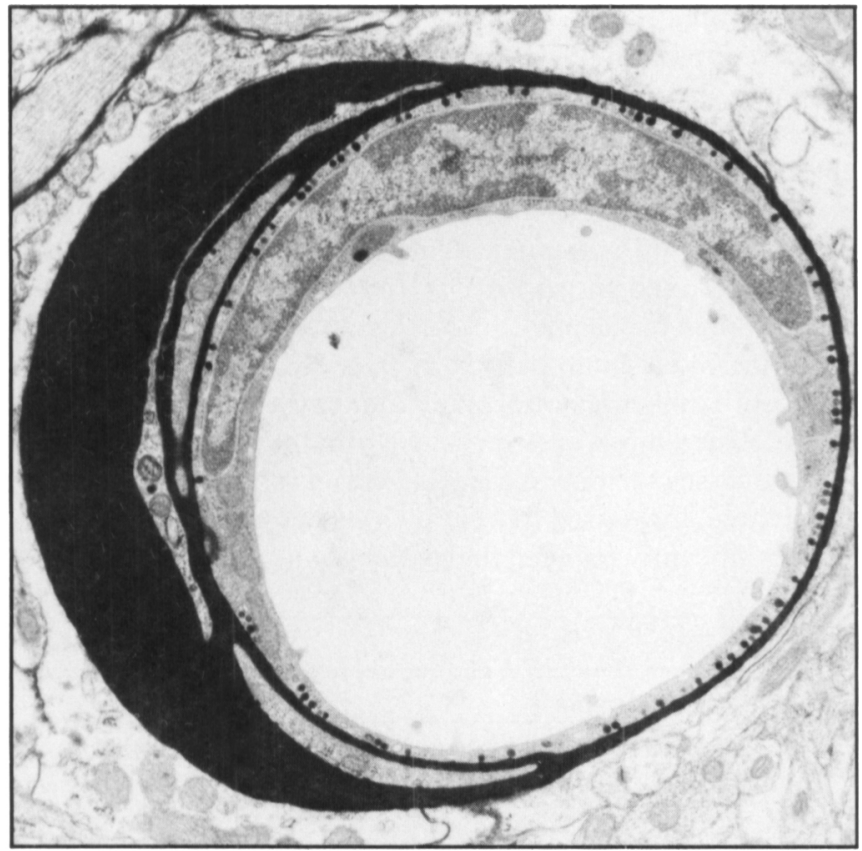

Figure 6-Small arteriole from Group 2. Mag. $\times$ 9,300. Note the swelling of surrounding astrocytes and the large accumulation of $H R P$ reaction product in the vessel wall.

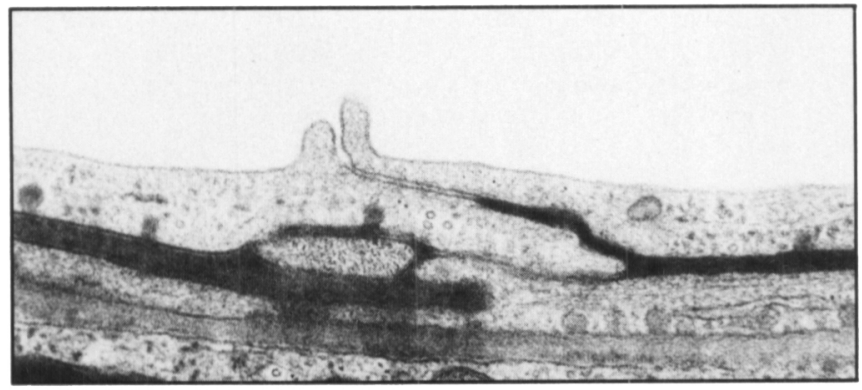

Figure $7-$ Mag. $\times$ 44,000. Permeable arteriole from Group 2 containing several positive pinocytotic vesicles and an intact tight junction. in medium, and a 1.5 fold increase $(p<0.002)$ in large arterioles over equivalent vessels in Group 1. This increase in pinocytotic vesicle density is better demonstrated by Figure 9 in which the values observed in all the arterioles are shown.

A regression line has been plotted for each group studied. The regression line for Group 1 has a slight positive slope of +0.0344 showing a tendency for the number of pinocytotic vesicles per $\mu \mathrm{m}^{2}$ to increase with vessel diameter. Group 2 has a negative slope of -0.2911 demonstrating the increased density of pinocytotic vesicles in the small arterioles in this model of BBB breakdown. This line is significantly different to that of Group I $(p<0.001)$.

Imidazole pretreatment (Group 3) did not prevent the increase in density of pinocytotic vesicles compared to bradykinin infusion alone (Group 2 Table 1). There was a 2.7 fold increase in the small vessels $(p<0.02), 1.6$ fold $(p<0.02)$ in medium vessels and a 1.4 fold $(p<0.002)$ increase in the large arterioles over vesicle density in Group 1. The slope of the regression line is -0.2210 ; slightly less than that of Group 2 but not significantly different. Regression lines from Groups 1 and 3 are significantly different at $\mathrm{p}<0.001$ level.

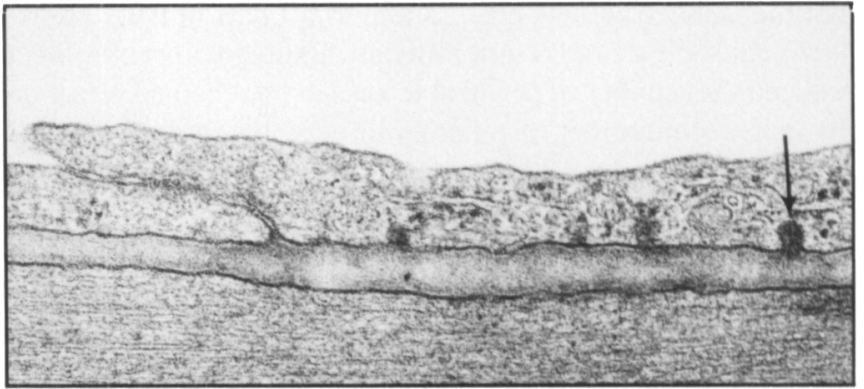

Figure 8-Mag. $\times$ 45,200, Group 3. Arteriole in the initial stage of becoming permeable. Note the HRP-containing vesicle "dumping " reaction product into the subendothelial space (arrow).

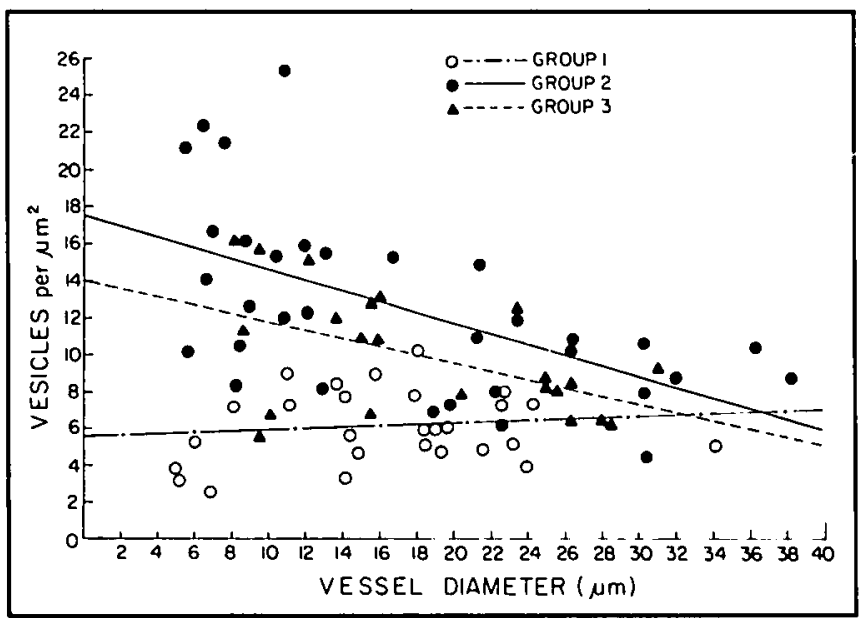

Figure 9 - Density of pinocytotic vesicles in arteriolar endothelium

Group I ( $\mathrm{NaCl}) \quad$ slope $=0.0344 \pm 0.1172 r^{+}=-.0365(27)$

Group 2 (Bradykinin) slope $=-0.2911 \pm 0.1492 r=-.5656(33) *$

Group 3 (Imidazole pretreatment + bradykinin)

slope $=-0.2210 \pm 0.1766 r=-.5021(22) *$

Numbers of vessels studied is given in brackets.

+ correlation coefficient

* significantly different from Group I where $p<0.001$

Group 2 is not significanty different from Group 3 
In both groups infused with bradykinin, the smaller vessels demonstrated a large increase in pinocytotic vesicles. This increase was examined more closely (Table 1 ) by comparing the numbers of vesicles containing HRP reaction product (positive vesicles) and the remaining vesicles (negative vesicles). Vessels in Group I contained the occasional positive vesicle; the number was greatest in the small arterioles $\left(0.26 / \mu^{2}\right.$ compared to 0.03 and $0.04 / \mu^{2}$ in larger vessels). This represents $6 \%$ of the vesicles in small vessels and less than $1 \%$ of vesicles in larger vessels.

In bradykinin infused rats (Groups 2 and 3 ) the number of negative pinocytotic vesicles remained the same, regardless of the size of the vessel $\left(2.4-3.0\right.$ vesicles $\left./ \mu \mathrm{m}^{2}\right)$. It is therefore the number of HRP-containing vesicles that was increased, and in small vessels these made up $80 \%$ of the pinocytotic vesicles in both Groups 2 and 3 . This figure was reduced to $73 \%$ (Group 2) and 66\% (Group 3) in the large vessels.

The density of negative vesicles in the medium and larger vessels of Groups 2 and 3 was reduced by $60 \%$ compared with Group 1 ( $p<0.001)$. Small vessels showed an insignificant decrease in negative pinocytotic vesicles.

In conclusion, both LM and EM observations demonstrate that the smaller vessels play an important part in BBB breakdown caused by bradykinin infusion. Imidazole pretreatment reduced the number of permeable vessels, but had no effect on the increased number of pinocytotic vesicles formed in these vessels.

\section{Discussion}

This model of BBB disruption in which bradykinin is infused via the internal carotid artery consistently lowered mean aortic blood pressure to a small extent. This observation agrees with the general peripheral vessel dilatation caused by bradykinin. ${ }^{8}$ Whalley and Wahl ${ }^{18}$ and Wahl and co-workers ${ }^{21}$ found that topical application of bradykinin $(0.1-100 \mu \mathrm{M})$ to cat pial arteries in situ caused a significant dilatation. The same authors observed a similar result with isolated cat and dog middle cerebral arteries; the maximum dilation occurring with $10^{-6} \mathrm{M}$ bradykinin. ${ }^{17.18}$ In contrast, a pressor action has been observed after bradykinin injection into the lateral ventricle of rats. ${ }^{11.13}$ It is uncertain whether this pressor effect is linked to renin release or angiotensin II and may be quite unrelated to the vasodilatory action of bradykinin.

Indomethacin pretreatment reduces the fall in blood pressure caused by prostaglandin release ${ }^{22}$ during renal infusion of bradykinin. ${ }^{23}$ However, prostaglandins are not the sole mediators of arterial relaxation by bradykinin ${ }^{24}$ additional compounds such as "endothelium releasing factor" ${ }^{\prime 24}$ and lipoxygenases ${ }^{25.26}$ are thought to mediate arterial relaxation. It is not surprising that indomethacin, a prostaglandin inhibitor, failed to reduce the drop in blood pressure caused by intracarotid bradykinin infusion.

The breakdown of the BBB by bradykinin infusion was extensive. Arterial hypotension may play a small part in this disruption, but it cannot be entirely responsible because the three drugs used in our experiments significantly reduced the extent of BBB damage but did not alter the pattern of MAP change. Bradykinin increases microvascular permeability, ${ }^{27}$ in the brain, a similar pattern is observed in which the small arterioles appear to be most affected. Acute hypertension causes a different pattern of BBB breakdown, in which larger arterioles $100-200 \mathrm{~nm}$ from the cortical surface are most heavily involved. ${ }^{2}$ This change in pattern is unlikely to be due to different circulation times of the tracer HRP, since both models show mainly discrete lesions in which the HRP is restricted to vessel walls and has not had sufficient time to leak into the parenchyma.

Unterberg and co-workers ${ }^{16.10}$ found that topical application of bradykinin to pial and cortical vessels caused selective opening of the blood brain barrier. In later studies they found that intraventricular infusion of bradykinin causes cerebral edema. ${ }^{15}$ These observations are consistent with the swollen astrocytic foot processes surrounding leaking vessels present in our model.

All three drugs used to treat the rats before bradykinin infusion significantly reduced the number of leaking vessels. Indo-

Table 1: Density of pinocytotic vesicles with and without HRP, per $\mu \mathrm{m}^{2}$ of endothelial cytoplasm

\begin{tabular}{|c|c|c|c|c|c|c|c|c|c|c|}
\hline & \multicolumn{3}{|c|}{ Small } & \multicolumn{3}{|c|}{ Medium } & \multicolumn{4}{|c|}{ Large } \\
\hline & \multicolumn{3}{|c|}{ (diameter $<10 \mu \mathrm{m})$} & \multicolumn{3}{|c|}{ (diameter $<10-18 \mu \mathrm{m})$} & \multicolumn{4}{|c|}{ (diameter $>18 \mu \mathrm{m})$} \\
\hline & Mean & S.D. & \#vessels & Mean & S.D. & \#vessels & Mean & & S.D. & \#vessels \\
\hline \multicolumn{11}{|l|}{ Group I ( $\mathrm{NaCl})$} \\
\hline -ve vesicles & 4.22 & 1.7 & (5) & 6.96 & 1.96 & (9) & 5.98 & & 1.66 & (13) \\
\hline + ve vesicles & 0.26 & 0.24 & (5) & 0.04 & 0.06 & (9) & 0.03 & & 0.04 & (13) \\
\hline Total & 4.48 & 1.80 & & 7.0 & 1.99 & & 6.01 & & 1.69 & \\
\hline$\%+$ ve vesicles & 5.8 & & & 0.6 & & & 0.5 & & & \\
\hline \multicolumn{11}{|c|}{ Group 2 (Bradykinin) } \\
\hline -ve vesicles & 2.96 & 0.93 & (10) & $2.59 * * *$ & 0.90 & (8) & 2.51 & $* * *$ & 0.73 & (15) \\
\hline+ ve vesicles & $11.92^{* * *}$ & 5.06 & & $12.37^{* * *}$ & 5.33 & & 6.70 & $* * *$ & 2.26 & \\
\hline Total & $14.88^{* * *}$ & 5.03 & & $14.96^{* *}$ & 4.90 & & 9.21 & $* * *$ & 2.58 & \\
\hline$\%+$ ve vesicles & 80.1 & & & 82.7 & & & 72.7 & & & \\
\hline \multicolumn{11}{|c|}{ Group 3 (Imidazole pretreat. and Bradykinin) } \\
\hline -ve vesicles & 2.41 & 1.34 & (4) & $2.73 * * *$ & 1.13 & $(8)$ & 2.73 & $* * *$ & 0.89 & $(10)$ \\
\hline + ve vesicles & $9.68 * * *$ & 4.06 & & $8.21 * * *$ & 2.66 & & 5.34 & $* * *$ & 1.46 & \\
\hline Total & $12.09 *$ & 5.00 & & $10.94 *$ & 3.00 & & 8.13 & * & 1.83 & \\
\hline$\%+$ ve vesicles & 80.1 & & & 75.0 & & & 65.7 & & & \\
\hline
\end{tabular}

* Significantly different from Group I where $p<0.02$

** Significantly different from Group 1 where $p<0.002$

*** Significantly different from Group 1 where $p<0.001$ 
methacin probably acts by preventing cerebral prostaglandin formation. ${ }^{28}$ It may also diminish the increase in $\mathrm{CBF}^{29}$ stimulated by prostaglandin formation.

TFP inhibits several calmodulin regulated enzymes which are involved in membrane transport including adenylate cyclase ${ }^{30}$ and calcium ATPase activity. ${ }^{31}$ This inhibition may enable TPF to stabilize cell membranes in culture ${ }^{32.33}$ and reduce phagocytosis. ${ }^{34}$ TFP reduces BBB disruption in acute hypertension ${ }^{6}$ and following a cold lesion; ${ }^{7}$ suppression of pinocytosis was suggested as a possible mechanism in both models. Calmodulin activates phospholipase $\mathrm{A}_{2}{ }^{35}$ an enzyme involved in prostaglandin production ${ }^{36}$ and TFP can inhibit prostaglandin synthesis stimulated by bradykinin in aortic endothelial cells. ${ }^{37}$ Therefore, TFP may suppress prostaglandin production, and reduce pinocytosis.

Imidazole inhibits the increase in intraocular pressure induced by prostaglandin ${ }^{38.39}$, prevents prostaglandin accumulation in urate arthritis ${ }^{40}$ and may therefore suppress the action of bradykinin. It activates phosphodiesterase which converts cAMP to $5^{\prime}$ AMP. ${ }^{41}$ Westergaard ${ }^{42}$ and Joo $^{43}$ suggested that cAMP regulates pinocytosis in cerebral endothelium. Imidazole may reduce tissue levels of $\mathrm{CAMP}$, and in turn reduce pinocytosis. This theory was suggested as a mechanism for imidazole action in reducing albumin extravasation during acute hypertension by Johansson ${ }^{6}$ and following a cold lesion. ${ }^{7}$ Imidazole may have a similar action in our model, since bradykinin has been reported to increase levels of cAMP in tissue. ${ }^{44}$

We found a great increase in the numbers of pinocytotic vesicles in vessels containing HRP. The total number of vesicles noted in the present study for vessels over $18 \mu \mathrm{m}$ in diameter agrees closely to that obtained by Nag and co-workers ${ }^{2}$ for both permeable ( 9.2 compared to $\left.9.9 / \mu \mathrm{m}^{2}\right)$ and control vessels $\left(6.0\right.$ compared to 5.1 vesicles $\left./ \mu \mathrm{m}^{2}\right)$. However, the small permeable vessels had a much higher density of vesicles $\left(14.9 / \mu \mathrm{m}^{2}\right)$ which represents a $50 \%$ increase over large permeable vessels and almost a 3 fold increase over small control vessels. The number of negative vesicles in these vessels remained at $3.0 / \mu \mathrm{m}^{2}$, of which some are probably invaginations of the plasma membrane, and not true pinocytotic vesicles. ${ }^{45}$ Thus over $80 \%$ of the vesicles in small leaking arterioles appear to be transporting material across the BBB. This figure is reduced slightly in larger vessels. All tight junctions observed in this study appeared intact so it is unlikely that HRP is reaching the subendothelial space via endothelial junctions as suggested by Huttner et al. ${ }^{46}$

Imidazole reduced the length of leaking vessels; the methods used did not measure the actual number of vessels involved. However, when the permeable sections of these vessels were examined by EM, the density of positive vesicles was not reduced. This suggests that when a vessel becomes permeable to HRP in this model, it is an all-or-nothing mechanism. Imidazole appears to be acting by preventing the arterioles from becoming permeable, not in reducing the rate at which they transport material.

The dose of indomethacin and TFP per $\mathrm{kg}$ used in these experiments is approximately five times greater than the recommended clinical dose. Since rats require higher drug levels to achieve a similar response to that seen in large animals and humans, ${ }^{47}$ the effects we observed could well take place in a clinical situation. It is possible that indomethacin or trifluoperazine could be used in the treatment of cerebral edema due to hypertension, or in other forms of cerebral edema; studies now underway will address this problem.

To conclude, bradykinin infusion produced extensive BBB breakdown which was significantly reduced by pretreatment with imidazole, TFP or indomethacin. There was extensive involvement of the small arterioles which contained the highest numbers of positive vesicles. Imidazole, though reducing the number of leaking vessels, did not prevent the increase in positive vesicles.

\section{ACKNOWLEDGEMENTS}

Supported by Medical Research Council Grant \# 1647. Trifluorperazine was the gift of Apotex Inc., Weston. Ontario. Canada.

\section{REFERENCES}

1. Hansson HA, Johansson BB, Blomstrand C. Ultrastructural studies on cerebrovascular permeability in acute hypertension. Acta Neuropathol 1975: 32: 187-198.

2. Nag S, Robertson DM, Dinsdale HB. Quantitative estimate of pinocytosis in experimental acute hypertension. Acta Neuropathol 1979: 46: 107-116.

3. Hansson HA, Johansson BB. Induction of pinocytosis in cerebral vessels by acute hypertension and by hyperosmolar solutions. J Neurosci Res 1980; 5: 183-190.

4. Baker RN. Cancilla PA. Pollock PS, et al. The movement of exogenous protein in experimental cerebral edema. An electron microscopic study after freeze injury. J Neuropathol Exp Neurol 1971; 30: 668-679.

5. Mitchell J, Weller RO, Evans H. Re-establishment of the bloodbrain barrier to peroxidase following cold injury to mou se cortex. Acta Neuropathol 1979: 46: 45-49.

6. Johansson BB. Pharmacological modification of hypertensive bloodbrain barrier opening. Acta Pharmacol Toxicol 1981: 48: 242-247.

7. Raymond JJ, Robertson DM, Dinsdale HB et al. Pharmacological modification of blood-brain barrier permeability following a cold lesion. Can J Neurol Sci 1984; 11: 447-451.

8. Haddy FJ, Emerson TE Jr, Scott JB et al. The effects of kinins on the cardiovascular system. In: Erdos EG, ed. Handbook of experimental pharmacology. Bradykinin, Kalladin and Kallekrein. New York: Springer-Verlag 1970; 25: 362-384.

9. Perry DC, Snyder SH. Identification of bradykinin in mammalian brain. J Neurochem 1984; 43: 1072-1080.

10. Unterberg A, Wahl M, Baethmann A. Effects of bradykinin on cerebrovascular permeability and resistance. J Cereb Blood Flow Metab 1983; 3 Suppl 1: S234-S235.

11. Iwata $\mathrm{T}$, Hashimoto $\mathrm{H}$, Hiwada $\mathrm{K}$ et al. Changes of plasma renin activity by intracerebroventricular administration of biological active peptides in conscious rats. Clin Exp Theory Practice 1984; A6: 1055-1066.

12. Lambert GA, Lang WJ. The effects of bradykinin and eledoisin injected into the cerebral ventricles of conscious rats. Eur J Pharmacol 1970; 9: 383-386.

13. Lewis RE, Phillips MI. Localization of the central pressor action of bradykinin to the cerebral third ventricle. Am J Physiol 1984: 247: R63-R68.

14. Kontos HA, Wei EP, Povlishock JT et al. Oxygen radicals mediate the cerebral arteriolar dilation from arachidonate and bradykinin in cats. Circ Res 1984: 55: 295-303.

15. Unterberg A, Baethmann AJ. The kallikrein-kinin system as mediator in vasogenic brain edema. Part 1: Cerebral exposure to bradykinin and plasma. J Neurosurg 1984; 61: 87-96.

16. Unterberg A, Wahl M, Baethmann A. Effects of bradykinin on blood-brain barrier function and pial microcirculation. In: Jensen HP. Brock M. Klinger M, eds. Advances in Neurosurgery. Berlin: Springer-Verlag 1983; 11: 355-358.

17. Toda N. Actions of bradykinin on isolated cerebral and peripheral arteries. Am J Physiol 1977; 232: H267-H274. 
18. Whally ET, Wahl M. The effect of kinase II inhibitors on the response of feline cerebral arteries to bradykinin and angiotensin. Pflugers Arch 1983; 398: 175-177.

19. Graham RC Jr, Karnovsky MJ. The early stages of absorption of injected horseradish peroxidase in the proximal tubules of mouse kidney: Ultrastructural cytochemistry by a new technique. J Histochem Cytochem 1966: 14: 291-302.

20. Venable JH, Coggeshall R. A simplified lead citrate stain for use in electron microscopy. J Cell Biol 1965; 25: 407-410.

21. Wahl M. Young AR, Edvinsson L et al. Effects of bradykinin on pial arteries and arterioles in vitro and in situ. J Cerebral Blood Flow Metab 1983: 3: 231-237.

22. McGiff JC, Itskovitz HD, Terragno NA. The actions of bradykinin and eledoisin in the canine isolated kidney: relationships to prostaglandins. Clin Sci Mol Med 1975: 49: 125-131.

23. Suzuki M, Satoh S. Suppression of bradykinin-induced renin release by indomethacin in anaesthetized rats. Clin and Exp Hypertension Theory and Prac 1984; A6: 1227-1235.

24. Cherry PD, Furchgott RF, Zawadzki JV et al. Role of endothelial cells in relaxation of isolated arteries by bradykinin. Proc Natl Acad Sci USA 1982; 79: 2106-2110.

25. Chand N, Altura BM. Endothelial cells and relaxation of vascular smooth muscle cells: possible relevance to lipoxygenesases and their significance in vascular diseases. Microcirculation 1981; 1 : 297-317.

26. Vanhoutte PM. Functional role of the endothelial cells. J Pharmacol 1983: 14: Suppl III, 73-79.

27. Gawlowski DM, Ritter AB. Duran WN. Reproducibility of microvascular permeability responses to successive topical applications of bradykinin in the hampster cheek pouch. Microvasc Res 1982: 24: 354-363.

28. Abdel-Halim MS, Sjoquist B, Anggard E. Inhibition of prostaglandin synthesis in rat brain. Acta Pharmacol Toxicol 1978: 43: 266-272

29. McCulloch J, Kelly PAT. Grome JJ et al. Local cerebral circulatory and metabolic effects of indomethacin. Am J Physiol 1982; 243: H416-H423.

30. Seaman KB, Daly JW. Calmodulin stimulation of adenylate cyclase in rat brain membranes does not require GTP. Life Sci 1982; 30: 1457-1464.

31. Lichtman AH, Segel GB, Lichtman MA. Effects of Trifluoperazine and mitogenic lectins on calcium ATPase activity and calcium transport by human lymphocyte plasma membrane vesicles. J Cell Physiol 1982; 111: 213-217.

32. Poste G, Reeve P. Inhibition of virus-induced cell fusion by local anaesthetics and phenothiazine tranquillizers. J Gen Virol 1972; 16: $21-28$.
33. Connor CG, Brady RC, Brownstein BL. Trifluoperazine inhibits spreading and migration of cells in culture. J Cell Physiol 1981: 108: 299-307.

34. Horwitz SB, Chia GH, Harracksingh Cet al. Trifluoperazine inhibits phagocytosis in a macrophage-like cultured cell line. J Cell Biol 1981; 91: 798-802.

35. Moskowitz N, Shapiro L, Schook $W$ et al. Phospholipase $A_{2}$ modulation by calmodulin, prostaglandins and cyclic nucleotides Biochem Biophys Res Comm 1983; 115: 94-99.

36. Flower RJ, Blackwell GJ. The importance of phospholipase - $A_{2}$ in prostaglandin biosynthesis. Biochem Pharmacol 1976: 25: 285-291.

37. Whorton AR, Willis CE, Kent RS et al. The role of calcium in the regulation of prostacyclin synthesis by porcine aortic endothelial cells. Lipids 1984: 19: 17-24.

38. Zink HA, Podos SM, Becker B. Inhibition by imidazole of the increase in intraocular pressure induced by topical prostaglandin E. Nature (New Biol) 1973; 245: 21-22.

39. Zink HA, Podos SM, Becker B. Modification by imidazoles of ocular inflammatory and pressure responses. Invest Ophthalmol 1975; 14: 280-285.

40. Peskar BA, Glatt M, Anhut $\mathrm{H}$ et al. Effect of imidazole on prostaglandin and thromboxane accumulation in urate arthritis. Eur J Pharmacol 1978; 50: 437-441.

41. Goodman HM. Metabolic effects of imidazole in adipose tissue. Biochim Biophys Acta 1969; 176: 60-64.

42. Westergaard $E$. The effect of serotonin, norepinephrine and cyclic AMP on the blood-brain barrier. J Ultrastruct Res 1975:50:383.

43. Joo FZ, Rakonczay Z, Wolleman M. cAMP-mediated regulation of the permeability in the brain capillaries. Experientia 1975:31: 582-584.

44. Bareis DL, Manganiello VC, Hirata F et al. Bradykinin stimulates phospholipid methylation. calcium influx, prostaglandin formation. and cAMP accumulation in human fibroblasts. Proc Natl Acad Sci USA 1983; 80: 2514-2518.

45. Bundgaard M. Vesicular transport in capillary endothelium: does it occur? Federation Proc 1983; 42: 2425-2430.

46. Huttner I, Boutet M, Rona G et al. Studies on protein passage through arterial endothelium. III Effect of blood pressure levels on the passage of fine structural protein tracers through rat arterial endothelium. Lab Invest 1973: 29: 536-546.

47. Barnes CD. Drug dosage in laboratory animals. a handbook. Berkley: University of California Press 1973. 